\title{
EPHX1 Tyr113His and His139Arg polymorphisms in esophageal cancer risk: a meta-analysis
}

\author{
X. Tan ${ }^{1 *}$, W.W. He ${ }^{1 *}$, Y.Y. Wang ${ }^{1}$, L.J. Shi ${ }^{2}$ and M.W. Chen ${ }^{1}$ \\ ${ }^{1}$ Department of Cardiothoracic Surgery, First Affiliated Hospital, \\ Guangxi Medical University, Nanning, Guangxi, China \\ ${ }^{2}$ Department of Oncology, Cancer Affiliated Hospital, \\ Guangxi Medical University, Nanning, Guangxi, China \\ *These authors contributed equally to this study. \\ Corresponding author: M.W. Chen \\ E-mail: chen535@126.com
}

Genet. Mol. Res. 13 (1): 649-659 (2014)

Received January 11, 2013

Accepted May 17, 2013

Published January 28, 2014

DOI http://dx.doi.org/10.4238/2014.January.28.10

\begin{abstract}
Microsomal epoxide hydrolase 1 (EPHX1) is an important biological phase II metabolic enzyme that is extensively involved in the metabolism of diverse environmental carcinogens such as polycyclic aromatic hydrocarbons and heterocyclic amines. Many articles have reported the association between EPHX1 (Tyr113His and His139Arg) polymorphisms and esophageal cancer risk, but the results are controversial. This study aimed to identify the association between EPHX1 (Tyr113His and His139Arg) polymorphisms and esophageal cancer risk by meta-analysis. The odds ratio (OR) with $95 \%$ confidence interval $(95 \% \mathrm{CI})$ was used to evaluate the strength of the associations. Heterogeneity was estimated by the chi-square-based Q-statistic test and the P value. Meanwhile, the random-effect or fixed-effect model was used according to the between-study heterogeneity. Begg's funnel plot and the Egger test were performed to assess the publication bias of articles. Finally, 8 case-control studies involving 1158 cases and 1868 controls
\end{abstract}


for the Tyr113His polymorphism and 7 case-control studies involving 901 cases and 1615 controls for the His139Arg polymorphism were included in this meta-analysis. Meta-analysis showed that the Tyr113His polymorphism was a stronger power trend towards risk for esophageal cancer using a recessive model (CC versus $\mathrm{CT}+\mathrm{TT}, \mathrm{OR}=1.204,95 \% \mathrm{CI}$ $=1.001-1.450, \mathrm{P}=0.049)$. However, no significant associated risk was found between the His139Arg polymorphism and esophageal cancer. These findings suggest that the Tyr113His polymorphism might be a stronger power trend towards risk for esophageal cancer. However, no evidence was found for the association between the EPHX1 His139Arg polymorphism and esophageal cancer risk.

Key words: EPHX1; Polymorphism; Esophageal cancer; Meta-analysis

\section{INTRODUCTION}

Among human cancers, esophageal cancer (EC), with a 5-year survival rate of less than $20 \%$, is regarded as one of the most common lethal malignancies worldwide. In particular, in the "esophageal cancer belt", which stretches from North Central China westward through Central Asia to northern Iran, the incidence is quite high (Akbari et al., 2006). The incidence and mortality of EC have been listed as eighth and sixth, respectively, of all cancers (Jemal et al., 2008, 2011). The main histological subtypes are squamous cell carcinoma (ESCC) and adenocarcinoma (EAC). The epidemiology is different; ESCC is widely distributed in Southern Russia and Southeastern Africa and Asia, and adenocarcinoma is widely distributed in Western Europe, Australia, and North America. In the "esophageal cancer belt", the most common histology of the squamous cell cancer has even reached $90 \%$ (Wheeler and Reed, 2012). Alcohol, smoking, age, gender, racial or ethnic group, areca chewing, and gastroesophageal reflux disease may be risk factors of EC (Yu et al., 1988; Farrow et al., 2000). However, not all exposed persons develop EC, suggesting that genetic factors may play a role in the development of EC.

Human carcinogens first pass Phase I metabolism enzyme activation to produce widely and highly active intermediates. Next, the active intermediates are subjected to detoxification by Phase II enzymes. Microsomal epoxide hydrolase (EPHX1) is the phase-II xenobiotic biotransformation enzyme that plays a dual effect in the detoxification and activation of procarcinogens (Casson et al., 2006). The Tyr113His (exon 3) and His139Arg (exon 4) EPHX1 variants have been identified in the protein sequences. These mutations correspond to 2 genetic polymorphisms of T/C (Tyr113His) in exon 3 and A/G (His139Arg) in exon 4, respectively (Hassett et al., 1994). In exon 3, the 113His allele of the enzyme results in a decrease in the activity of approximately $50 \%$ (slow allele), whereas the exon $4 \operatorname{Arg} 139$ allele causes an increase in the activity of $25 \%$ (fast allele) (Hassett et al., 1994; Pinarbasi et al., 2010). The variations of the EPHX1 enzyme activity may lead to inter-individual variations in the susceptibility to mutagenic, carcinogenic, or teratogenic processes.

The EPHX1 gene is located in the long arm of chromosome 1 and is extensively expressed in the lungs, upper gastrointestinal tract, and other organs (Voho et al., 2006). Given the know variations of the EPHX1 gene, the polymorphisms may strongly affect cancer risk, 
such as lung cancer, colorectal cancer, upper aerodigestive tract cancers, and ovarian cancer (Harrison et al., 1999; Jourenkova-Mironova et al., 2000; Spurdle et al., 2001; Park et al., 2005).

Recent studies have suggested that T113C and A139G polymorphisms might clarify the causes and events correlated with EC, but the results were conflicting and inconclusive. Therefore, a meta-analysis was conducted to investigate the relationship between $\mathrm{T} 113 \mathrm{C}$ and A139G polymorphisms and susceptibility to EC.

\section{MATERIAL AND METHODS}

\section{Search strategy and selection criteria}

A comprehensive systematic bibliographic search was performed using PubMed, Embase, and Cochrane for all medical publications until November 1, 2012, with the following terms: microsomal epoxide hydrolase 1, mEH, EPHX1, Tyr113His, exon 3, codon 113, T113C, rs1051740, His139Arg, exon4, codon 139, A139G, rs2234922, polymorphism, variant; and "esophagus" or "esophageal" combined with "carcinoma", "cancer", "squamous cell", or "adenocarcinoma". All human studies fulfilled the following criteria: 1) full-text articles, 2) using case-control study, 3) investigation of EPHX1 Tyr113His and His139Arg polymorphisms and esophageal cancer, 4) sufficient data for estimating an odds ratio (OR) with a $95 \%$ confidence interval $(95 \% \mathrm{CI}), 5)$ sufficient genotype data can be obtained, 6) and report written in English.

\section{Data extraction}

Study selection and data extraction were performed independently by 2 investigators (X. Tan and W.W. He). Cases of disagreement were discussed and then resolved. If the 2 investigators could not resolve the case, a third investigator (M.W. Chen) made the decision. The data items included first author, year of publication, country, ethnicity, sample size, diagnostic criteria, source of controls, study design, genotyping method, and different genotype counts in all studies.

\section{Statistical analysis}

The pooled risk OR and 95\%CI of EC associated with Tyr113His and His139Arg polymorphisms were calculated for each study. To avoid using a specific genetic model and thus outcome bias, at least 3 possible genotypes were compared in the meta-analysis of genetic associations. For example, for Tyr113His, we estimated the OR of a cancer associated with a codominant model (CC versus TT, CT versus TT), dominant model $(\mathrm{CC}+\mathrm{CT}$ versus $\mathrm{TT})$, and recessive model ( $\mathrm{CC}$ versus $\mathrm{CT}+\mathrm{TT})$.

Between-study heterogeneity was estimated by the chi-square-based Q-statistic test and the $\mathrm{P}$ value (Higgins et al., 2003). If $\mathrm{P}>0.1$ and $\mathrm{I}^{2}<25 \%$, study heterogeneity did not exist. If there was no heterogeneity, the overall gene effect was evaluated by the fixed-effect model according to the Mantel-Haenszel method (Mantel and Haenszel, 1959). When $\mathrm{I}^{2}>50 \%$ or $\mathrm{P}$ $<0.1$, the heterogeneity was considered to be statistically significant, and sensitivity analysis was used for excluding studies that had potential bias; the random-effect model according to the DerSimonian and Laird method was applied if heterogeneity still existed (Lau et al., 1997). 
Potential publication bias was investigated by Begg's funnel plot, and the unweighted funnel plot was applied using a regression test (Peters et al., 2006). To evaluate the effects of covariance subgroup analyses were performed due to geographical and ethnic differences as well as the pathological type of EC. Ethnic subgroups were divided into Caucasian and Asian, while pathological subgroups were categorized into ESCC and EAC. All analyses were performed using Stata version 11.1 (StataCorp., College Station, TX, USA). All of the P values were two-sided, and $\mathrm{P}<0.05$ was considered to be statistically significant.

\section{RESULTS}

\section{Characteristics of relevant studies}

Our search strategy and inclusion criteria (the publication selection process is shown in Figure 1), 8 studies were identified with full-text articles that remained with association between EPHX 1 (Tyr113His and His139Arg) polymorphisms and EC (Zhang et al., 2003; Wang et al., 2003; Casson et al., 2003, 2006; Lin et al., 2006; Jain et al., 2008; Ihsan et al., 2010; Dura et al., 2012). Among the included articles, 7 articles provided separate data for the EPHX1 Tyr113His and EPHX1 His139Arg polymorphisms (Wang et al., 2003; Casson et al., 2003, 2006; Lin et al., 2006; Jain et al., 2008; Ihsan et al., 2010; Dura et al., 2012), which were treated as 2 separate studies. Finally, 8 articles including a total of 1158 cases and 1868 controls included studies of the Tyr113His polymorphism, whereas 7 articles including 901 cases and 1615 controls included studies of the His139Arg polymorphism.

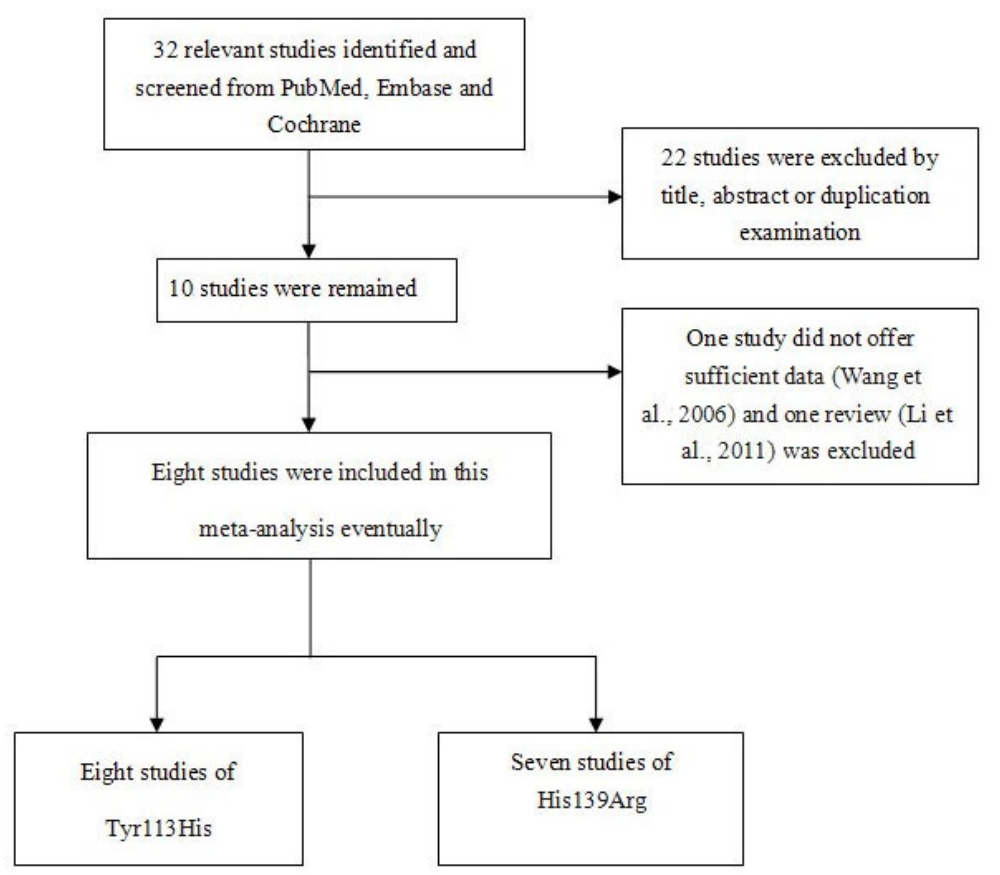

Figure 1. Publication selection process of this meta-analysis. 
To evaluate the effects of covariance, subgroup analyses were performed. For 1 study (Dura et al., 2012), including 2 pathologic types, ESCC and EAC, the data were collected separately and served as independent studies in the subgroup analyses. Thus, there were 9 studies on the Tyr113His polymorphism and 8 studies on the His139Arg polymorphism for ESCC and EAC. However, in the ethnic subgroup analysis, there were 5 studies in Asian (Zhang et al., 2003; Wang et al., 2003; Lin et al., 2006; Jain et al., 2008; Ihsan et al., 2010) and 3 studies in Caucasian (Casson et al., 2003, 2006; Dura et al., 2012). Among the 8 studies, a polymerase chain reaction-restriction fragment length polymorphism (PCR-RFLP) assay was performed in 5 studies (Zhang et al., 2003; Wang et al., 2003; Lin et al., 2006; Jain et al., 2008; Ihsan et al., 2010). The remaining 3 studies used PCR (Casson et al., 2003, 2006; Dura et al., 2012). The source of the controls are hospital-based, and the diagnostic criteria are listed in Table 1. The genotype distributions of all studies are shown in Table 2 .

\section{Meta-analysis results}

The main results of the meta-analysis of the association between Tyr113His and His139Arg polymorphisms and EC risk are shown in Tables 3 and 4, respectively.

For the Tyr113His polymorphism, although the statistical significance was not obvious, we found a stronger power trend towards risk for $\mathrm{EC}(\mathrm{C}$ versus $\mathrm{T}, \mathrm{OR}=1.139,95 \% \mathrm{CI}=$ $0.942-1.377, \mathrm{P}=0.178 ; \mathrm{CC}$ versus $\mathrm{TT}, \mathrm{OR}=1.073,95 \% \mathrm{CI}=0.867-1.329, \mathrm{P}=0.516 ; \mathrm{CT}$ versus TT, $\mathrm{OR}=0.934,95 \% \mathrm{CI}=0.642-1.358, \mathrm{P}=0.720$; recessive model $\mathrm{CC}$ versus $\mathrm{CT}+\mathrm{TT}$, OR $=1.204,95 \% \mathrm{CI}=1.001-1.450, \mathrm{P}=0.049$; dominant model $\mathrm{CC}+\mathrm{CT}$ versus $\mathrm{TT}, \mathrm{OR}=1.066$, $95 \% \mathrm{CI}=0.773-1.468, \mathrm{P}=0.697)$. To assess the covariance effects, ethnicity and histological typing were performed by subgroup analyses. However, in the ethnic subgroup analysis, no significant risk association was found for any genetic models between the EPHX1 Tyr113His polymorphism and Caucasian and Asian populations. We also did not detect any significant simultaneously association between the EPHX1 Tyr113His polymorphism and ESCC and EAC in the subgroup histological type analysis (Table 3).

Overall, the EPHX1 His139Arg polymorphism was not significantly associated with an increased risk of $\mathrm{EC}$ ( $\mathrm{G}$ versus $\mathrm{A}, \mathrm{OR}=1.059,95 \% \mathrm{CI}=0.908-1.236, \mathrm{P}=0.464$; $\mathrm{GG}$ versus $\mathrm{AA}, \mathrm{OR}=1.340,95 \% \mathrm{CI}=0.848-2.117, \mathrm{P}=0.210 ; \mathrm{AG}$ versus $\mathrm{AA}, \mathrm{OR}=1.174,95 \% \mathrm{CI}=$ $0.806-1.712, \mathrm{P}=0.403$; recessive model $\mathrm{GG}$ versus $\mathrm{AG}+\mathrm{AA}, \mathrm{OR}=1.047,95 \% \mathrm{CI}=0.727$ $1.506, \mathrm{P}=0.345$; dominant model $\mathrm{GG}+\mathrm{AG}$ versus $\mathrm{AA}, \mathrm{OR}=1.174,95 \% \mathrm{CI}=0.821-1.679$, $\mathrm{P}=0.379$ ). Similarly, in subgroup analyses for the His139Arg polymorphism, risk associated with EC was not found for either ethnicity (Caucasian and Asian) or histological type (ESCC and EAC) (Table 4).

\section{Tests for heterogeneity, sensitivity, and publication bias}

Using the recessive model, there was no obvious between-study heterogeneity observed for EPHX1. In contrast, using the codominant and dominant models, heterogeneity was obvious. Sensitivity analysis was performed in our meta-analysis. When we omitted every study at each time, the reanalysis results for the EPHX1 His139Arg polymorphism were stable; for the EPHX1 Tyr113His polymorphism, the result fluctuated somewhat, but there was still a risk for EC (data not show). 
X. Tan et al.

654

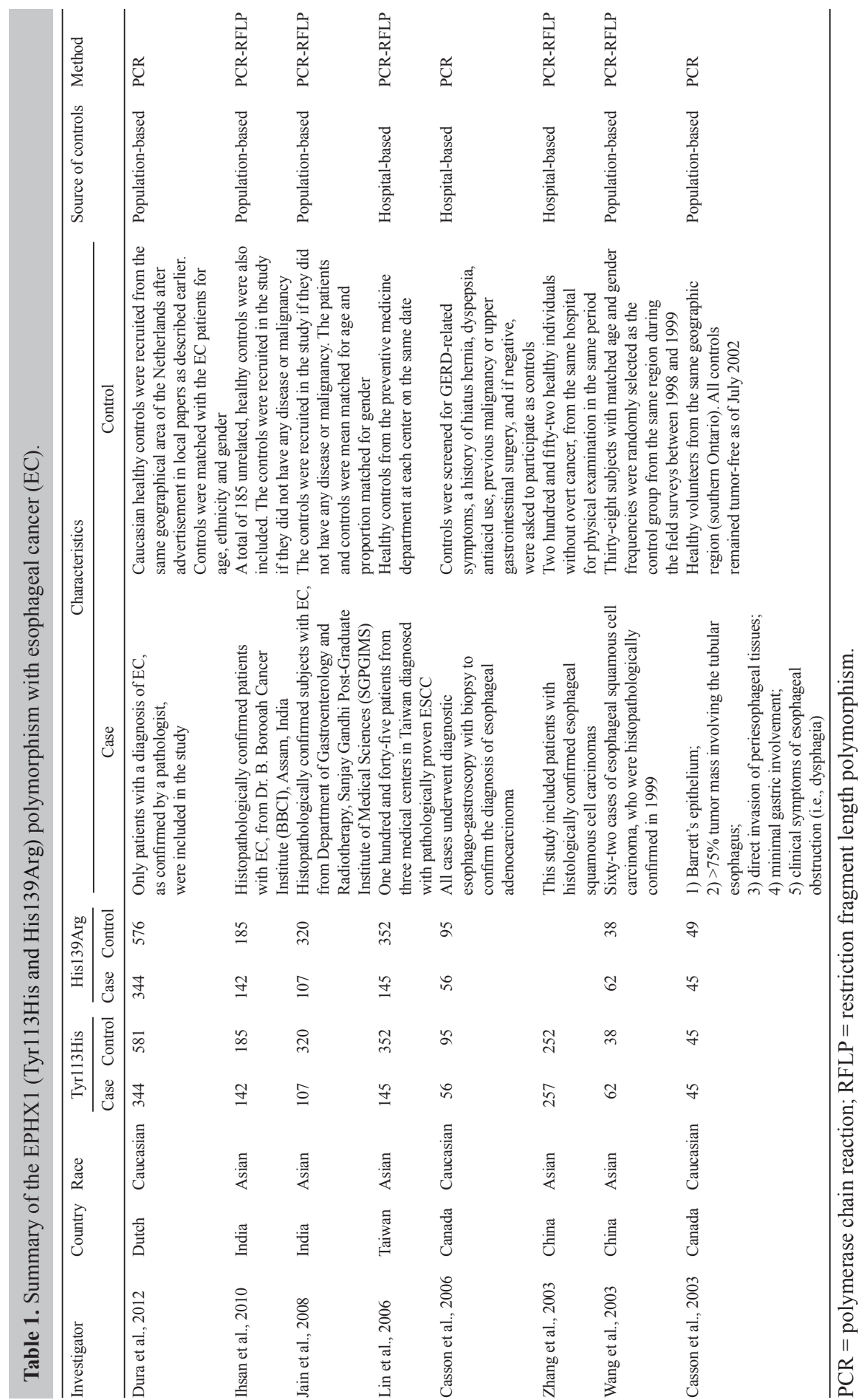


Table 2. Genotype distribution of all studies in this meta-analysis.

\begin{tabular}{lcccccc}
\hline Investigator & \multicolumn{3}{c}{ Tyr113His (case/control) } & & \multicolumn{2}{c}{ His139Arg (case/control) } \\
\cline { 2 - 4 } & CC & TC & TT & GG & AG & AA \\
\hline Dura et al., 2012 & $30 / 58$ & $136 / 228$ & $178 / 295$ & $11 / 25$ & $111 / 187$ & $222 / 364$ \\
Ihsan et al., 2010 & $38 / 34$ & $49 / 96$ & $55 / 55$ & $7 / 2$ & $87 / 138$ \\
Jain et al., 2008 & $13 / 31$ & $66 / 156$ & $28 / 133$ & $7 / 17$ & $29 / 116$ & $71 / 187$ \\
Lin et al., 2006 & $42 / 105$ & $51 / 140$ & $52 / 107$ & $0 / 0$ & $28 / 65$ & $117 / 287$ \\
Casson et al., 2006 & $34 / 42$ & $16 / 34$ & $6 / 19$ & $35 / 55$ & NA & $1 / 7$ \\
Zhang et al., 2003 & $115 / 105$ & $58 / 71$ & $84 / 76$ & NA & $1 / 1 / 5$ & NA \\
Wang et al., 2003 & $17 / 5$ & $22 / 10$ & $23 / 23$ & $1 / 13$ & $16 / 8$ \\
Casson et al., 2003 & $26 / 21$ & $10 / 20$ & $9 / 4$ & $28 / 34$ & $1 / 7$ \\
\hline
\end{tabular}

$\mathrm{NA}=$ not available.

Table 3. Main results of the meta-analysis EPHX1 Tyr113His relationship with esophageal cancer.

\begin{tabular}{|c|c|c|c|c|c|c|c|c|c|c|c|c|c|}
\hline \multirow[t]{2}{*}{ Variable } & \multirow[t]{2}{*}{$\mathrm{N}$} & \multicolumn{3}{|c|}{ His/His vs Tyr/Tyr } & \multicolumn{3}{|c|}{ His/Tyr vs Tyr/Tyr } & \multicolumn{3}{|c|}{ Dominant model } & \multicolumn{3}{|c|}{ Recessive model } \\
\hline & & OR $(95 \% \mathrm{CI})$ & $\mathrm{P}^{\mathrm{a}}$ & $\mathrm{P}^{\mathrm{b}}$ & OR $(95 \% \mathrm{CI})$ & $\mathrm{P}^{\mathrm{a}}$ & $\mathrm{P}^{\mathrm{b}}$ & OR $(95 \% \mathrm{CI})$ & $\mathrm{P}^{\mathrm{a}}$ & $\mathrm{P}^{\mathrm{b}}$ & OR $(95 \% \mathrm{CI})$ & $\mathrm{P}^{\mathrm{a}}$ & $\mathrm{P}^{\mathrm{b}}$ \\
\hline Total & 8 & $\begin{array}{c}1.073 \\
(0.867-1.329)\end{array}$ & 0.092 & 0.516 & $\begin{array}{c}0.934 \\
(0.642-1.358)\end{array}$ & 0.001 & 0.720 & $\begin{array}{c}1.066 \\
(0.773-1.468)\end{array}$ & 0.002 & 0.697 & $\begin{array}{c}1.204 \\
(1.001-1.450)\end{array}$ & 0.286 & 0.049 \\
\hline \multicolumn{14}{|l|}{ Ethnicity } \\
\hline Caucasian & 3 & $\begin{array}{c}0.994 \\
(0.666-1.483)\end{array}$ & 0.108 & 0.977 & $\begin{array}{c}0.814 \\
(0.366-1.809)\end{array}$ & 0.088 & 0.613 & $\begin{array}{c}0.990 \\
(0.505-1.940)\end{array}$ & 0.115 & 0.976 & $\begin{array}{c}1.185 \\
(0.843-1.664)\end{array}$ & 0.201 & 0.328 \\
\hline Asian & 5 & $\begin{array}{c}1.107 \\
(0.86-1.424)\end{array}$ & 0.107 & 0.432 & $\begin{array}{c}0.991 \\
(0.582-1.688)\end{array}$ & 0.001 & 0.973 & $\begin{array}{c}1.118 \\
(0.712-1.756)\end{array}$ & 0.001 & 0.627 & $\begin{array}{c}1.213 \\
(0.972-1.513)\end{array}$ & 0.286 & 0.087 \\
\hline \multicolumn{14}{|l|}{ Histopathology } \\
\hline ESCC & 6 & $\begin{array}{c}1.081 \\
(0.851-1.375)\end{array}$ & 0.160 & 0.523 & $\begin{array}{c}0.956 \\
(0.624-1.466)\end{array}$ & 0.002 & 0.838 & $\begin{array}{c}1.057 \\
(0.731-1.529)\end{array}$ & 0.003 & 0.767 & $\begin{array}{c}1.188 \\
(0.961-1.468)\end{array}$ & 0.465 & 0.111 \\
\hline EAC & 3 & $\begin{array}{c}1.014 \\
(0.66-1.558)\end{array}$ & 0.111 & 0.948 & $\begin{array}{c}0.829 \\
(0.365-1.880)\end{array}$ & 0.082 & 0.653 & $\begin{array}{c}1.011 \\
(0.515-1.985)\end{array}$ & 0.118 & 0.975 & $\begin{array}{c}1.213 \\
(0.848-1.734)\end{array}$ & 0.121 & 0.290 \\
\hline
\end{tabular}

EPHX1 Tyr113His; $\mathrm{N}=$ number of studies in each analysis; Dominant model $=$ His/His + His/Tyr $v s$ Tyr/Tyr; Recessive model $=\mathrm{His} / \mathrm{His} v \mathrm{His} / \mathrm{Tyr}+\mathrm{Tyr} / \mathrm{Tyr}$; OR $=$ odds ratio; $95 \% \mathrm{CI}=95 \%$ confidence interval; ${ }^{\text {aP }}$ value

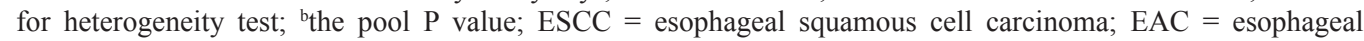
adenocarcinoma.

\begin{tabular}{|c|c|c|c|c|c|c|c|c|c|c|c|c|c|}
\hline \multirow[t]{2}{*}{ Variable } & \multirow[t]{2}{*}{$\mathrm{N}$} & \multicolumn{3}{|c|}{ Arg/Arg vs His/His } & \multicolumn{3}{|c|}{$\mathrm{Arg} / \mathrm{His} v s \mathrm{His} / \mathrm{His}$} & \multicolumn{3}{|c|}{ Dominant model } & \multicolumn{3}{|c|}{ Recessive model } \\
\hline & & OR $(95 \% \mathrm{CI})$ & $\mathrm{P}^{\mathrm{a}}$ & $\mathrm{P}^{\mathrm{b}}$ & OR $(95 \% \mathrm{CI})$ & $\mathrm{P}^{\mathrm{a}}$ & $\mathrm{P}^{\mathrm{b}}$ & OR $(95 \% \mathrm{CI})$ & $\mathrm{P}^{\mathrm{a}}$ & $\mathrm{P}^{\mathrm{b}}$ & OR $(95 \% \mathrm{CI})$ & $\mathrm{P}^{\mathrm{a}}$ & $\mathrm{P}^{\mathrm{b}}$ \\
\hline Total & 7 & $\begin{array}{c}1.340 \\
(0.848-2.117)\end{array}$ & 0.099 & 0.210 & $\begin{array}{c}1.174 \\
(0.806-1.712)\end{array}$ & 0.026 & 0.403 & $\begin{array}{c}1.174 \\
(0.821-1.679)\end{array}$ & 0.030 & 0.379 & $\begin{array}{c}1.047 \\
(0.727-1.506)\end{array}$ & 0.345 & 0.806 \\
\hline \multicolumn{14}{|l|}{ Ethnicity } \\
\hline Caucasian & 3 & $\begin{array}{c}1.177 \\
(0.650-2.132)\end{array}$ & 0.144 & 0.590 & $\begin{array}{c}2.905 \\
(0.521-16.215)\end{array}$ & 0.031 & 0.224 & $\begin{array}{c}2.262 \\
(0.535-9.563)\end{array}$ & 0.066 & 0.267 & $\begin{array}{c}0.890 \\
(0.583-1.359)\end{array}$ & 0.519 & 0.589 \\
\hline Asian & 4 & $\begin{array}{c}1.629 \\
(0.796-3.334)\end{array}$ & 0.179 & 0.182 & $\begin{array}{c}1.093 \\
(0.691-1.727)\end{array}$ & 0.060 & 0.704 & $\begin{array}{c}1.136 \\
(0.712-1.811)\end{array}$ & 0.042 & 0.593 & $\begin{array}{c}1.708 \\
(0.833-3.503)\end{array}$ & 0.276 & 0.144 \\
\hline \multicolumn{14}{|c|}{ Histopathology } \\
\hline ESCC & 5 & $\begin{array}{c}1.287 \\
(0.705-2.347)\end{array}$ & 0.214 & 0.411 & $\begin{array}{c}0.990 \\
(0.671-1.46)\end{array}$ & 0.051 & 0.959 & $\begin{array}{c}1.021 \\
(0.683-1.527)\end{array}$ & 0.028 & 0.918 & $\begin{array}{c}1.374 \\
(0.753-2.509)\end{array}$ & 0.323 & 0.301 \\
\hline EAC & 3 & $\begin{array}{c}1.273 \\
(0.674-2.406)\end{array}$ & 0.080 & 0.457 & $\begin{array}{c}2.961 \\
(0.577-15.195)\end{array}$ & 0.042 & 0.193 & $\begin{array}{c}2.284 \\
(0.589-8.865)\end{array}$ & 0.088 & 0.233 & $\begin{array}{c}0.894 \\
(0.576-1.385)\end{array}$ & 0.514 & 0.615 \\
\hline
\end{tabular}

EPHX1 His139Arg; $\mathrm{N}=$ number of studies in each analysis; Dominant model $=\mathrm{Arg} / \mathrm{Arg}+\mathrm{Arg} / \mathrm{His} v s \mathrm{His} /$ His; Recessive model $=\mathrm{Arg} / \mathrm{Arg} v s \mathrm{Arg} / \mathrm{His}+\mathrm{His} / \mathrm{His} ; \mathrm{OR}=$ odds ratio; 95\%CI $=95 \%$ confidence interval; ${ }^{\mathrm{a}} \mathrm{P}$ value for heterogeneity test; ${ }^{b}$ the pool $\mathrm{P}$ value; $\mathrm{ESCC}=$ esophageal squamous cell carcinoma; $\mathrm{EAC}=$ esophageal adenocarcinoma. 
Begg's funnel plot and the Egger test were performed to assess the publication bias of the articles. The results of both Begg and Egger tests did not show any evidence of publication bias (Tyr113His: CC vs TT Egger test, $\mathrm{P}=0.134$; TC $v s$ TT Egger test, $\mathrm{P}=0.937$; recessive model, Egger test, $\mathrm{P}=0.050$, dominant model, Egger test, $\mathrm{P}=0.525$; His139Arg: GG vs AA Egger test, $\mathrm{P}=0.125$; TC $v s$ TT Egger test, $\mathrm{P}=0.123$; recessive model, Egger test, $\mathrm{P}=0.532$, dominant model, Egger test, $\mathrm{P}=0.141$ ) (Begg test; data not show).

\section{DISCUSSION}

Our meta-analysis included 8 studies with a total of 1158 cases and 1868 controls that were used to evaluate the association between the Tyr113His polymorphism and EC; 7 studies including 901 cases and 1615 controls were used for the His139Arg polymorphism. Although the sample size is not sufficiently large, this is to our knowledge the first systematic review that has independently evaluated the relationship between the EPHX1 (Tyr113His and His 139Arg) polymorphisms and EC. Our meta-analysis provided evidence that the Tyr113His polymorphism might play an important role in EC under a recessive model $(\mathrm{OR}=1.204$, $95 \% \mathrm{CI}=1.001-1.450, \mathrm{P}=0.049<0.05$ ) (Figure 2). However, we found that the His139Arg polymorphism was not significantly associated with EC risk in the codominant, dominant, and recessive models (dominant model as show in Figure 3). No publication bias was revealed by the funnel plots, supporting our meta-analysis conclusions.

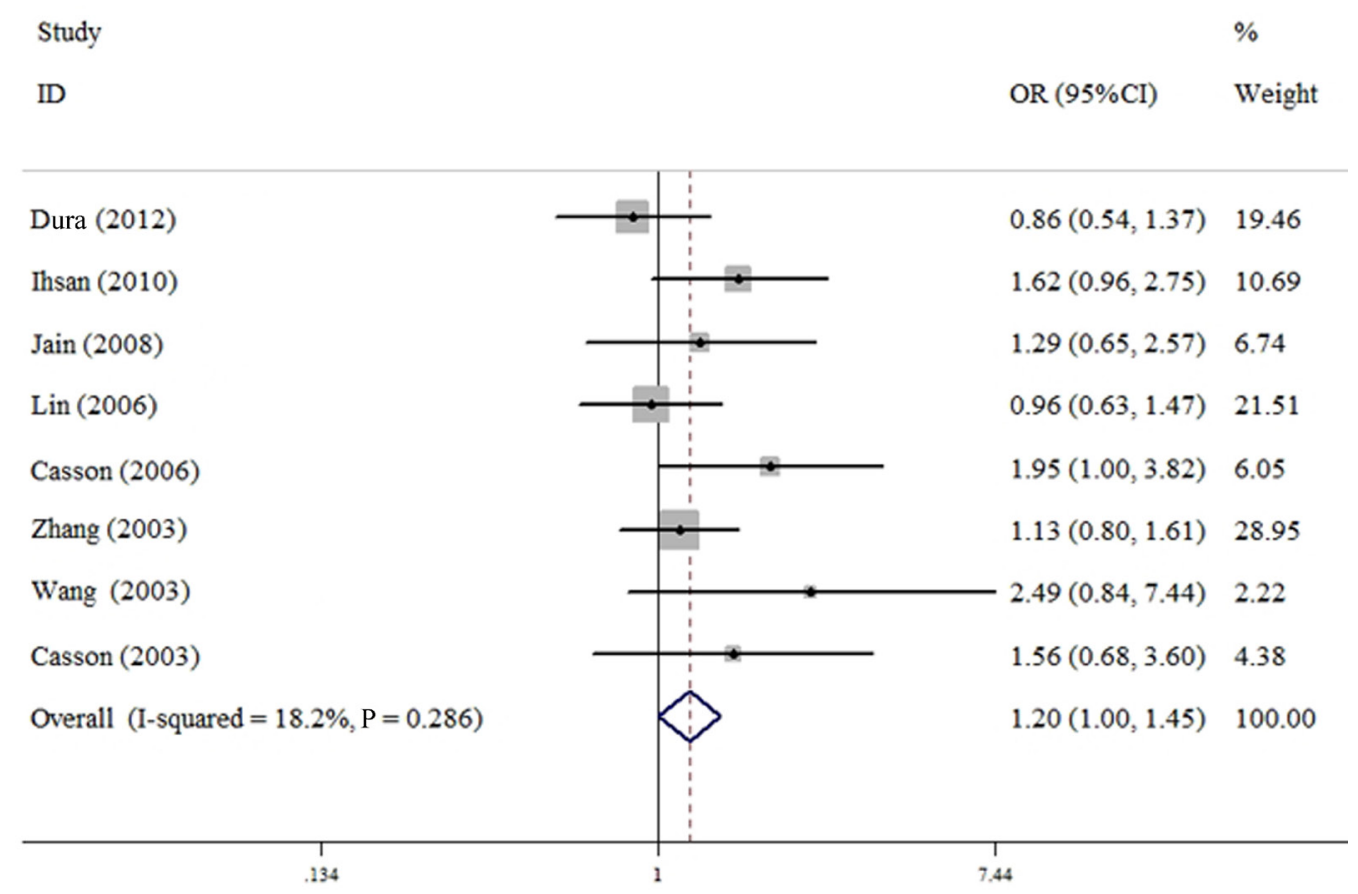

Figure 2. Forest plot describing the meta-analysis with a fixed-effect recessive model (CC $v s$ TC+TT) for the association of the EPHX1 Tyr113His polymorphism with esophageal cancer. Each study is depicted with size inversely proportional to its variance, accompanied by the respective $95 \%$ confidence intervals. 


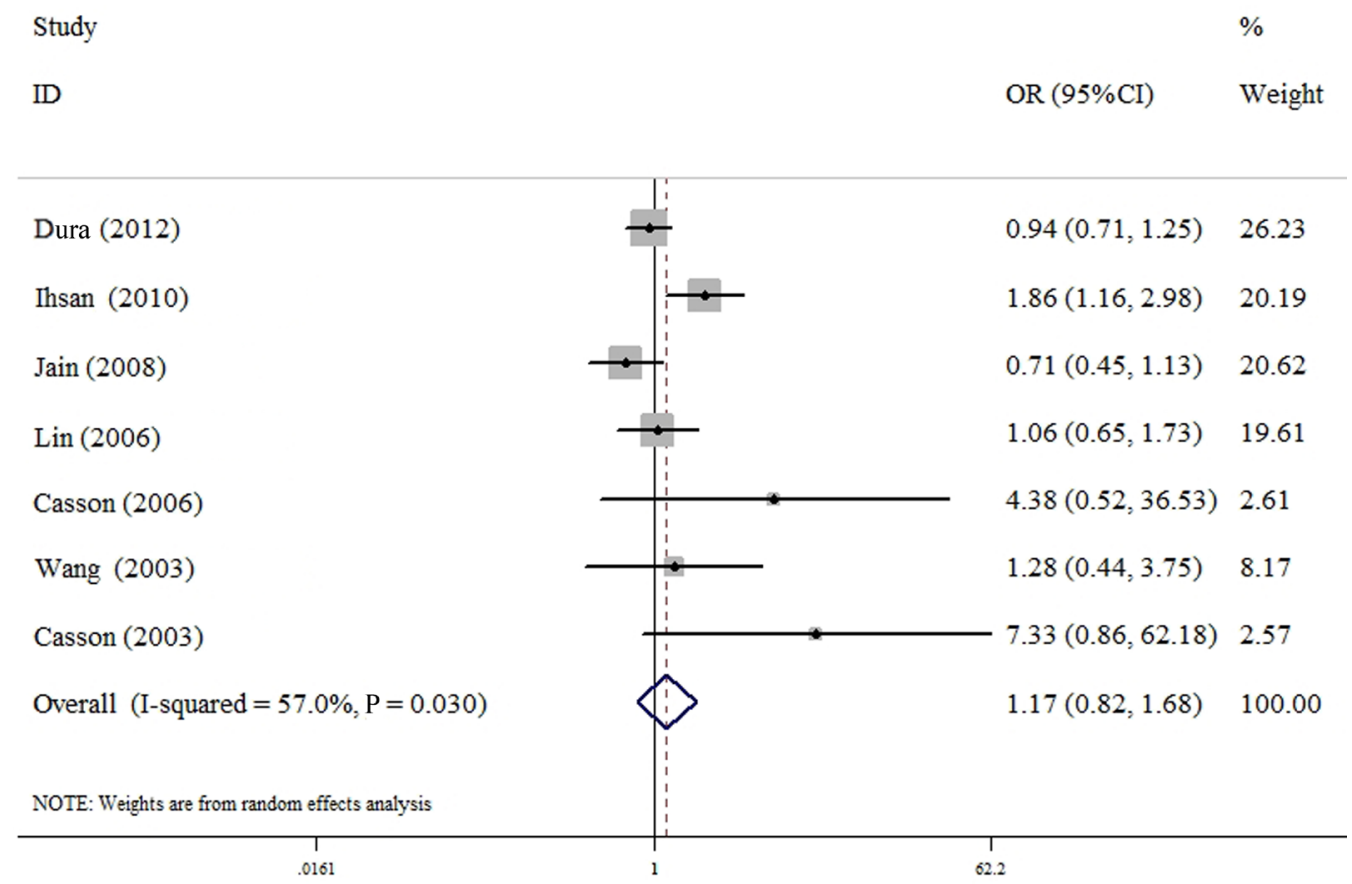

Figure 3. Forest plot describing the meta-analysis with a random-effect dominant model (GG+AG vs AA) for the association of the EPHX1 His139Arg polymorphism with esophageal cancer. Each study is depicted with size inversely proportional to its variance, accompanied by the respective $95 \%$ confidence interval.

EPHX1 is a crucial biotransformation enzyme, catalyzing the conversion of a series of xenobiotic epoxide substrates to more polar diol metabolites (Omiecinski et al., 2000). Because of the EPHX1 Tyr113His polymorphism, a slow 113His allele of the enzyme decreases the activity, which might decrease the detoxification of carcinogens, resulting in highly reactive intermediates and carcinogen-induced cancer (Kiyohara et al., 2006; Sivonova et al., 2012). Two studies (Wang et al., 2003; Jain et al., 2008) showed risk for association between the Tyr113His polymorphism and EC, whereas the others (Zhang et al., 2003; Casson et al., 2003, 2006; Lin et al., 2006; Ihsan et al., 2010; Dura et al., 2012) did not show any significant difference of developing EC. In addition, Ihsan et al. (2010) reported that the Tyr113His genotype was a protective factor in the Indian population. Our results indicated a correlation between the Tyr113His polymorphism and risk of EC.

In contrast to the Tyr113His polymorphism, His139Arg leads to an increased enzyme activity, which might promote more rapid detoxification of exogenous carcinogens. Three articles (Casson et al., 2003; Jain et al., 2008; Ihsan et al., 2010) indicated that the His139Arg polymorphism is associated with EC, whereas 4 studies revealed a contradictory result (Wang et al., 2003; Casson et al., 2006; Lin et al., 2006; Dura et al., 2012). According to our findings, this meta-analysis did not indicate a significant effect of the His139Arg polymorphism.

To prevent excessive evaluation of the true effect between the EPHX1 polymorphism and EC, we conducted subgroup analyses by ethnicity and histological type. We similarly found that EPHX1 (Tyr113His and His139Arg) polymorphism had no statistically significant 
relationship with EC based on ethnicity and histological type. This lack of significant relationship may be due to the low sample size or some other potentially suspected factors such as smoking status, alcohol consumption, history of gastroesophageal reflux disease, and lifestyle, which influence our research. Although we did not find any such associations, we cannot eliminate the possibility that an association exists in certain subgroups of individuals.

Although we made considerable efforts to collect all available data to study EPHX1 (Tyr113His and His139Arg) polymorphism correlation with EC risk, some limitations existed. First, present research articles describing associations between EPHX1 polymorphisms and EC risk are few, and therefore, the sample of participants included in our meta-analysis is comparatively small. Second, the source of the controls did not differ. Healthy controls recruited from the same geographical area acted as the reference group for some studies, whereas other studies selected hospital patients without organic EC as the reference group. Furthermore, age, gender, smoking status, cancer type, and ethnicity were not consistent in all studied subjects. As stated above, these factors may be sources of heterogeneity. Finally, the EPHX1 gene might influence susceptibility to EC with other factors, but we did not conduct relative research, such as the gene-gene and gene-environment interactions.

In conclusion, this meta-analysis did not find any evidence for the association between the EPHX1 His139Arg polymorphism and EC risk in the overall studies. However, we found that although statistical significance was barely observed, there was a stronger power trend towards risk for the Tyr113His polymorphism and EC. Meanwhile, gene-gene and gene-environmental interactions on EC risk may be involved because most data were insufficient; therefore, further studies with larger sample size and well-designed and high-quality case-control studies are required to investigate the associations between EPHX1 polymorphisms and EC.

\section{REFERENCES}

Akbari MR, Malekzadeh R, Nasrollahzadeh D, Amanian D, et al. (2006). Familial risks of esophageal cancer among the Turkmen population of the Caspian littoral of Iran. Int. J. Cancer 119: 1047-1051.

Casson AG, Zheng Z, Chiasson D, MacDonald K, et al. (2003). Associations between genetic polymorphisms of Phase I and II metabolizing enzymes, $p 53$ and susceptibility to esophageal adenocarcinoma. Cancer Detect. Prev. 27: 139-146.

Casson AG, Zheng Z, Porter GA and Guernsey DL (2006). Genetic polymorphisms of microsomal epoxide hydroxylase and glutathione S-transferases M1, T1 and P1, interactions with smoking, and risk for esophageal (Barrett) adenocarcinoma. Cancer Detect. Prev. 30: 423-431.

Dura P, Bregitha CV, Te Morsche RH, Roelofs HM, et al. (2012). EPHX1 polymorphisms do not modify esophageal carcinoma susceptibility in Dutch Caucasians. Oncol. Rep. 27: 1710-1716.

Farrow DC, Vaughan TL, Sweeney C, Gammon MD, et al. (2000). Gastroesophageal reflux disease, use of H2 receptor antagonists, and risk of esophageal and gastric cancer. Cancer Causes Control 11: 231-238.

Harrison DJ, Hubbard AL, MacMillan J, Wyllie AH, et al. (1999). Microsomal epoxide hydrolase gene polymorphism and susceptibility to colon cancer. Br. J. Cancer 79: 168-171.

Hassett C, Aicher L, Sidhu JS and Omiecinski CJ (1994). Human microsomal epoxide hydrolase: genetic polymorphism and functional expression in vitro of amino acid variants. Hum. Mol. Genet. 3: 421-428.

Higgins JP, Thompson SG, Deeks JJ and Altman DG (2003). Measuring inconsistency in meta-analyses. BMJ 327: 557-560.

Ihsan R, Chattopadhyay I, Phukan R, Mishra AK, et al. (2010). Role of epoxide hydrolase 1 gene polymorphisms in esophageal cancer in a high-risk area in India. J. Gastroenterol. Hepatol. 25: 1456-1462.

Jain M, Tilak AR, Upadhyay R, Kumar A, et al. (2008). Microsomal epoxide hydrolase (EPHX1), slow (exon 3, 113His) and fast (exon 4, 139Arg) alleles confer susceptibility to squamous cell esophageal cancer. Toxicol. Appl. Pharmacol. 230: 247-251.

Jemal A, Siegel R, Ward E, Hao Y, et al. (2008). Cancer statistics, 2008. CA Cancer J. Clin. 58: 71-96.

Jemal A, Bray F, Center MM, Ferlay J, et al. (2011). Global cancer statistics. CA Cancer J. Clin. 61: 69-90. 
Jourenkova-Mironova N, Mitrunen K, Bouchardy C, Dayer P, et al. (2000). High-activity microsomal epoxide hydrolase genotypes and the risk of oral, pharynx, and larynx cancers. Cancer Res. 60: 534-536.

Kiyohara C, Yoshimasu K, Takayama K and Nakanishi Y (2006). EPHX1 polymorphisms and the risk of lung cancer: a HuGE review. Epidemiology 17: 89-99.

Lau J, Ioannidis JP and Schmid CH (1997). Quantitative synthesis in systematic reviews. Ann. Intern. Med. 127: 820-826.

Li X, Hu Z, Qu X, Zhu J, et al. (2011). Putative EPHX1 enzyme activity is related with risk of lung and upper aerodigestive tract cancers: a comprehensive meta-analysis. PLoS One 6: e14749.

Lin YC, Wu DC, Lee JM, Hsu HK, et al. (2006). The association between microsomal epoxide hydrolase genotypes and esophageal squamous-cell-carcinoma in Taiwan: interaction between areca chewing and smoking. Cancer Lett. 237: 281-288.

Mantel N and Haenszel W (1959). Statistical aspects of the analysis of data from retrospective studies of disease. J. Natl. Cancer Inst. 22: 719-748.

Omiecinski CJ, Hassett C and Hosagrahara V (2000). Epoxide hydrolase - polymorphism and role in toxicology. Toxicol. Lett. 112-113: 365-370.

Park JY, Chen L, Elahi A, Lazarus P, et al. (2005). Genetic analysis of microsomal epoxide hydrolase gene and its association with lung cancer risk. Eur. J. Cancer Prev. 14: 223-230.

Peters JL, Sutton AJ, Jones DR, Abrams KR, et al. (2006). Comparison of two methods to detect publication bias in metaanalysis. JAMA 295: 676-680.

Pinarbasi H, Silig Y and Pinarbasi E (2010). Microsomal epoxide hydrolase polymorphisms. Mol. Med. Rep. 3: 723-727.

Sivonova MK, Dobrota D, Matakova T, Dusenka R, et al. (2012). Microsomal epoxide hydrolase polymorphisms, cigarette smoking and prostate cancer risk in the Slovak population. Neoplasma 59: 79-84.

Spurdle AB, Purdie DM, Webb PM, Chen X, et al. (2001). The microsomal epoxide hydrolase Tyr113His polymorphism: association with risk of ovarian cancer. Mol. Carcinog. 30: 71-78.

Voho A, Metsola K, Anttila S, Impivaara O, et al. (2006). EPHX1 gene polymorphisms and individual susceptibility to lung cancer. Cancer Lett. 237: 102-108.

Wang LD, Zheng S, Liu B, Zhou JX, et al. (2003). CYP1A1, GSTs and mEH polymorphisms and susceptibility to esophageal carcinoma: study of population from a high-incidence area in north China. World J. Gastroenterol. 9: 1394-1397.

Wang Z, Tang L, Sun G, Tang Y, et al. (2006). Etiological study of esophageal squamous cell carcinoma in an endemic region: a population-based case control study in Huaian, China. BMC Cancer 6: 287.

Wheeler JB and Reed CE (2012). Epidemiology of esophageal cancer. Surg. Clin. North Am. 92: 1077-1087.

Yu MC, Garabrant DH, Peters JM and Mack TM (1988). Tobacco, alcohol, diet, occupation, and carcinoma of the esophagus. Cancer Res. 48: 3843-3848.

Zhang JH, Jin X, Li Y, Wang R, et al. (2003). Epoxide hydrolase Tyr113His polymorphism is not associated with susceptibility to esophageal squamous cell carcinoma in population of North China. World J. Gastroenterol. 9: 2654-2657. 